\title{
Somatic condition determines female mating frequency in a field population of the grasshopper Eyprepocnemis plorans
}

\author{
A. MARTíN-ALGANZA†, M. D. LÓPEZ-LEÓN, J. CABRERO \& J. P. M. CAMACHO* \\ Departamento de Genética, Universidad de Granada, E-18071 Granada, Spain and †Max-Planck-Institut für \\ Verhaltensphysiologie, D-82319 Seewiesen, Germany
}

\begin{abstract}
Mating pairs and nonmating individuals of the grasshopper Eyprepocnemis plorans were collected in a natural population during the 1992 season, in order to determine whether sexual preferences of males and females are correlated with various morphological and physiological characters. These included condition based on body size and somatic and gonadal weight. A comparison of frequency distributions for these characters between the two types of individuals showed that mating frequency (the probability of being sampled while mating) was independent of the characters measured in males but was highly significantly dependent on somatic condition in females. Mating females showed a better somatic condition (defined as the residuals of the regression of somatic weight on body size) than nonmating ones. The implications of this finding in shaping the polygynandrous mating system of this species are discussed.
\end{abstract}

Keywords: body size, Eyprepocnemis plorans, grasshopper, sexual selection, somatic condition.

\section{Introduction}

Sexual size dimorphism is the result of differences in the net selection pressures acting on body size in both sexes (see Preziosi \& Fairbairn, 1996, for review). Both sexual and fecundity selection may be important factors enhancing sex differences in body size (Darwin, 1871). In species where males are the larger sex (some mammals) sexual selection for larger males who gain an advantage in contests over mates may be the major cause of sexual size dimorphism. However, in species where females are the larger sex (many insects) fecundity selection favouring larger females (which are able to mature and lay more eggs) is most likely the main determining factor (see Andersson, 1994, for review).

Premating sexual selection may occur at intra(mating competition) or intersexual (mate choice) levels, and similar levels are found for postmating sexual selection acting through sperm competition (intrasexual) and cryptic female choice (intersexual). Insect females usually store sufficient sperm to fertilize all the eggs they lay over their lifetime; however, they usually mate multiply (Ridley, 1988). To explain this behaviour it is necessary to ascertain the benefits they obtain from multiple mating. Possible advantages include: (i) an increase in fecundity derived from obtaining male ejaculate nutrients; (ii) an increase in fertility because of replenishment of

\footnotetext{
*Correspondence. E-mail: jpmcamac@goliat.ugr.es
}

sperm storage organs; and (iii) the avoidance of sterility resulting from mating with a single sterile male. These benefits explain why many insect females are prone to mate frequently despite the various disadvantages of mating in terms of predation and disease risks and the time and energy devoted to it. In polygynous mating systems, the best strategy for males to improve fertility is to achieve many matings with different females, although the benefits they obtain greatly depend on sperm competition devices (see Smith, 1984, for review). Because most insects do not establish stable pairbonds, it is expected that female multiple mating should give rise to polygynandrous mating systems as a logical consequence of both sexes trying to mate frequently.

The grasshopper Eyprepocnemis plorans is a clear example of an insect with a polygynandrous mating system. Males do not stridulate at all, thus differing from many other grasshopper species, so that mate finding and courtship seem to be essentially visual and pheromonal. Females store and maintain viable sperm for about 60 days (López-León et al., 1994). In the laboratory, females mate several times before the first egg-pod laying, but generally only once in each subsequent egg-pod cycle (Pardo et al., 1995a). They mate indiscriminately with different males, and there is evidence for multiple paternity among progeny of females mated in the field (López-León et al., 1995), although a high last-male sperm prece- 
dence is the norm (on average, 90 per cent of the progeny is sired by the last male mated to the female; López-León et al., 1993). Males incorporate proteinaceous nutrients into the ejaculate that passes to the female's body and these are incorporated into the eggs she subsequently lays, with a consequent increase in egg and embryo production (Pardo et al., 1995a).

The operation of natural and sexual selection in the field may be shown by a number of different methods (Arnold \& Wade, 1984a,b; Endler, 1986). The cross-sectional method consists of collecting individuals at different stages (young or adult) or status (breeding or nonbreeding; mating or nonmating) and comparing their frequency distributions for a number of characters. Recent examples using this method to detect premating sexual selection may be found in the fruit fly Drosophila buzzatii (Santos et al., 1988), the water strider Gerris odontogaster (Arnqvist, 1992) and the marine snail Littorina saxatilis (Johannesson et al., 1995).

The present paper aims to detect possible morphological and anatomical correlates of mating frequency in both sexes of the polygynandrous grasshopper Eyprepocnemis plorans in a natural population, using the cross-sectional method, by collecting a large number of individuals in two different mating states. The results revealed the absence of any relationship in males but a highly significant dependence of mating frequency on weight-based somatic condition in females.

\section{Materials and methods}

A total of 516 adult E. plorans were caught during October \& November (1992) in Salobreña (Granada, Spain). As copulation in this species lasts about $24 \mathrm{~h}$, it is relatively easy to collect mating pairs in natural populations; this means that in the Salobreña population, 10-20 mating pairs could be caught in a day in about $5 \mathrm{~h}$ sampling. Successive samplings were performed once or twice a week. Each sampling day, similar numbers of mating and nonmating individuals were caught. In total, 129 mating pairs, 129 nonmating males and 129 nonmating females were caught. In the first week of December a single couple was collected in one day of sampling and we decided not to perform additional sampling.

Each couple or nonmating individual was carried live to the laboratory in a small tube and weighed to the nearest $0.1 \mathrm{mg}$; after anaesthesia with ethyl acetate, the gonads were dissected out. Bodies were stored in 70 per cent ethanol and gonads were weighed and then stored in 1:3 acetic ethanol.

With the aid of a calliper, we measured the following metrical traits (to the nearest $0.05 \mathrm{~mm}$ ): (i) thorax length (TL); (ii) thorax width (TW); (iii) tegmina length (TGL); (iv) hind femur length (HFL); and (v) hind tibia length (HTL). In addition, with a stereomicroscope, we scored the following meristic traits: (i) the number of antennal segments (ASN); (ii) the number of testis follicles (TFN); (iii) the number of ovarioles (ON); and (iv) the number of developing eggs (DEN). Finally, egg length and width were measured in arbitrary units, using the image processor Leica Quantimet 500.

Statistical comparisons between mating and nonmating individuals were performed using two different approaches: (i) univariate analysis by means of the Student's $t$-test for variables showing a normal distribution or else the Mann-Whitney test for variables not showing a normal distribution (normality was tested by means of the ShapiroWilks test); in order to minimize Type I errors in these multiple tests, $P$-values were transformed into $P_{\mathrm{b}}$ values by using the sequential Bonferroni method; (ii) multivariate analysis, by means of logistic regression, a special case of multiple regression in which the dependent variable is binary (in our case, its two states were 'mating' and 'nonmating').

The present analysis provides information on whether or not individuals were mating at the time of collection, and does not necessarily translate into real mating success measured over a season or lifetime. It does, however, provide an indication of whether mating probability is related to morphological traits. To avoid confusion, we will use the term 'mating frequency' for our estimation, which is defined as the probability of an individual being sampled while mating (either 0 or 1) (Carroll \& Salamon, 1995).

\section{Results}

\section{Analysis of morphological variation}

A Principal Components Analysis (PCA) was first applied to summarize variation in a fewer set of variables that could be representative of body or gonad size. Three principal components (PCs) appeared in males: (i) PCI explained 44.55 per cent of total variance and was defined by thorax length, thorax width, tegmina length, femur length and tibia length; (ii) PCII explained 16.27 per cent and was associated with the number of testis follicles only; (iii) PCIII explained only 11.17 per cent and was 
exclusively attributable to variation in the number of antennal segments. PCI was thus a good indicator of body size whereas PCII and PCIII were univariate factors indicating testis and antenna structure, respectively, (Fig. 1a).

In females, however, there were four PCs: (i) PCI explained 35.41 per cent of variance and was linked to the same variables as PCI in males, thus being a body size indicator; (ii) PCII explained 23.24 per cent and was defined by egg length and egg width, thus being an indicator of egg size; (iii) PCIII explained 10.06 per cent and was attributable to the number of ovarioles and developing eggs, thus being an indicator of ovary structure; (iv) PCIV explained 8.93 per cent, reflecting the variation in the number of antennal segments exclusively (Fig. 1b).

These PCAs showed that several of the traits measured in both sexes should be combined in a lower number of variables. First, body size is well

(a)

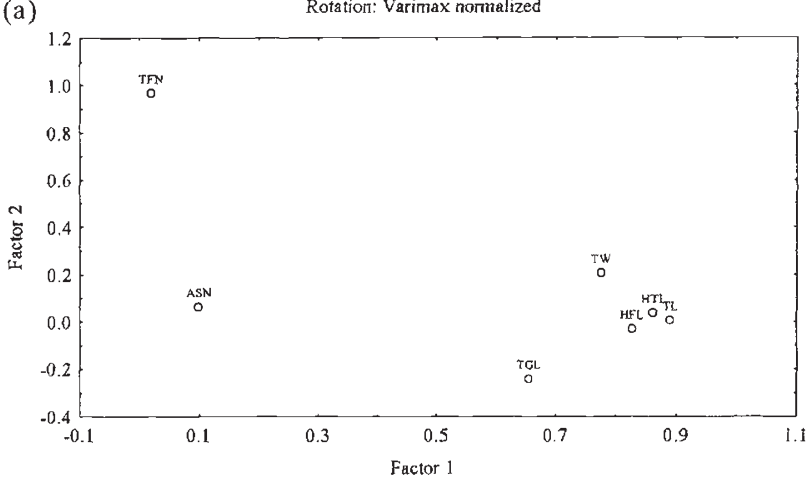

(b)

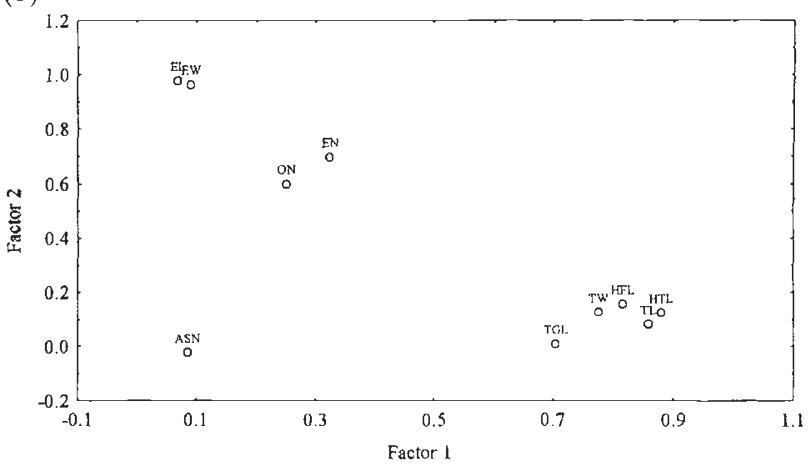

Fig. 1 Projection of all variables measured on Eyprepocnemis plorans on the first two axes of the Principal Components Analysis. (a) Males; (b) females. TL, thorax length; TW, thorax width; TGL, tegmina length; HFL, hind femur length; HTL, hind tibia length; ASN, number of antennal segments; TFN, number of testis follicles; EL, egg length; $\mathrm{EW}$, egg width; ON, ovariole number; EN, egg number. shown by the five morphometrical traits measured, but we consider that thorax length (TL) is the best trait for measuring body size in this species because: (i) it was the variable showing the highest factor loadings in PCI of both sexes; (ii) thorax measurements may be obtained in all specimens, in contrast to hind legs that are accidentally lost in some specimens so that the use of the femur and tibia reduce the sample size; (iii) tegmina tip is frequently worn away; (iv) thorax width shows ambiguous borders, but thorax length is very well delimited so that it may be reliably measured.

Secondly, PCII in females suggests that egg length and width should be combined in a single variable indicating egg size; we have approximated egg volume $(\mathrm{EV})$ to that of a cylinder.

Thirdly, the two variables included in PCIII in females, number of ovarioles and number of eggs, were combined as the proportion of ovarioles developing an egg (EDO). This is an index of the proportion of total reproductive potential actually employed by the female.

Fourthly, the total volume of eggs (TVE) was calculated as the product of egg volume and the number of eggs.

\section{Somatic and gonadal conditions}

Two additional body-weight-based variables were defined: somatic condition (SC) and gonadal condition (GC). SC was defined as the standardized residuals of the regression of somatic body weight (total body weight minus gonadal weight) on thorax length. Whereas SC was very well defined in both sexes (Fig. 2), with very significant regressions, GC was poorly defined, especially in males (males: $r=0.132, \mathrm{SE}=0.066, t_{223}=1.99, P=0.048$; females: $\left.r=0.200, \mathrm{SE}=0.062, t_{253}=3.24, P=0.001\right)$.

\section{Mating frequency}

In total, the variables used for comparisons between mating and nonmating individuals were $T L$, number of antennal segments (ASN), number of testis follicles (TFN), SC and GC in males, and TL, ASN, EDO, EV, TVE, SC and GC in females.

Univariate comparisons showed that mating and nonmating males did not differ significantly for any of the five variables compared (Table 1). In females, however, SC of mating females was highly significantly better than that of nonmating females $\left(P_{\mathrm{b}}=0.004\right.$; Table 2).

For logistic regression, we used only those variables that gave $P$-values lower than 0.3 in the singletrait comparisons. Table 3 shows that logistic 
regression confirms the results of the univariate comparisons, no differences between mating and nonmating males, and significantly better somatic condition in mating females (Fig. 3).

(a)

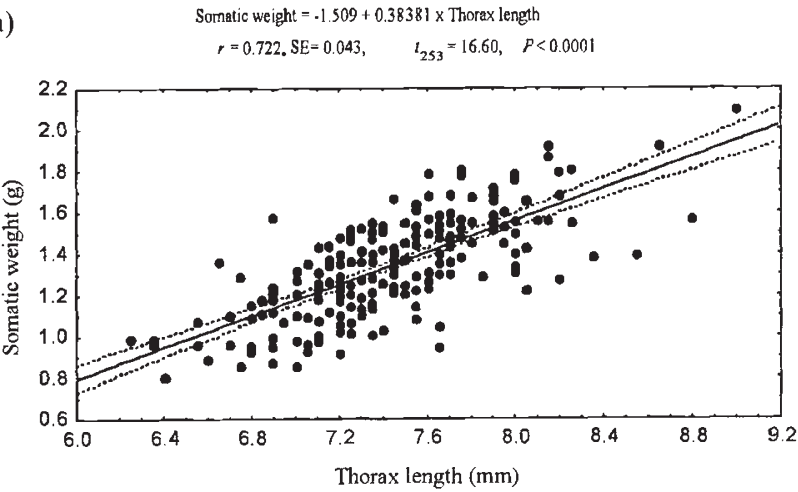

(b) Somatic weight $=-0.6295+0.214 \times$ Thora length $r=0.749, \mathrm{SE}=0.044, \quad t_{223}=16.89, \quad P<0.000$

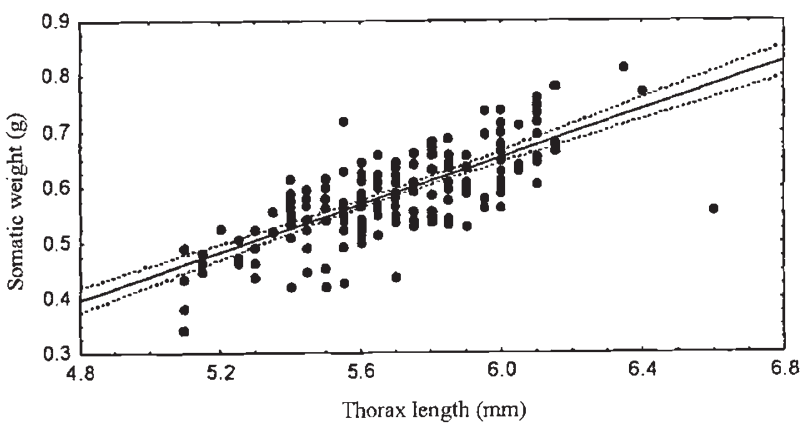

Fig. 2 Definition of somatic condition in Eyprepocnemis plorans as the standardized residuals of a regression of somatic weight on body size represented by thorax length.

(a) Males; (b) females.
Spearman nonparametric rank correlation analysis on the males and females collected as mating pairs showed that mating was random for the five traits analysed, thorax length, number of antennal segments, number of testis follicles and ovariole number, somatic condition and gonadal condition (data not shown).

\section{Discussion}

PCA analysis has shown that body size in E. plorans is well measured by thorax length, so that in the future this trait should be used as a body size index. This trait has been used in many species, e.g. Drosophila melanogaster (Pitnick, 1991), D. buzzatii (Ruiz et al., 1991), D. testacea (James \& Jaenike, 1992) and Gerris odontogaster (Arnqvist, 1992).

In some animal species body weight has been used as a measure of body size, e.g. in Neobellieria bullata (Berrigan \& Locke, 1991), Drosophila grimshawi (Droney, 1992) and Utetheisa omatrix (LaMunyon \& Eisner, 1993). Because body weight depends on both body size (expressed as length, volume, etc.) and body condition, it should be appropriate to use separately an index for body size and another for weight-based body condition which is independent of body size. In some cases, e.g. Gerris odontogaster (Arnqvist, 1992), body weight has been used as a condition index, but a distinction has rarely been made in the literature between body weight and condition, one of the few exceptions being the study by Bortolotti \& Iko (1992) in Falco sparverius.

As Trivers (1972) pointed out, body size is an indicator of strength and may be important for intrasexual competition. Condition, defined as weight related to size, is rather a quality index, the same as a variety of physical and behavioural attributes (Andersson, 1986; Hill, 1990). In the present study,

Table 1 Shapiro-Wilks test for normality $(W)$ and univariate tests (Student's $t$ or Mann-Whitney $U$ ) comparing five variables between mating and nonmating male Eyprepocnemis plorans

\begin{tabular}{|c|c|c|c|c|c|c|c|c|c|c|c|c|c|}
\hline \multirow[b]{2}{*}{ Trait } & \multicolumn{3}{|c|}{ Shapiro-Wilks } & \multicolumn{3}{|c|}{ Nonmating males } & \multicolumn{3}{|c|}{ Mating males } & \multicolumn{4}{|c|}{ Comparison } \\
\hline & $N$ & $W$ & $P$ & $N$ & Mean & SE & $N$ & Mean & SE & $t / z$ & d.f. & $P$ & $P_{\mathrm{b}}$ \\
\hline $\mathrm{TL}$ & 257 & 0.978 & 0.147 & 129 & 5.704 & 0.223 & 128 & 5.665 & 0.024 & 1.204 & 255 & 0.230 & - \\
\hline ASN & 257 & 0.688 & $<0.001$ & 129 & 25.302 & 0.116 & 128 & 25.375 & 0.117 & -0.423 & - & 0.673 & - \\
\hline TFN & 255 & 0.982 & 0.377 & 129 & 77.659 & 1.111 & 126 & 74.397 & 1.115 & 2.072 & 253 & 0.039 & 0.195 \\
\hline $\mathrm{SC}$ & 225 & 0.983 & 0.535 & 121 & -0.064 & 0.098 & 104 & 0.074 & 0.088 & -1.034 & 223 & 0.302 & - \\
\hline GC & 225 & 0.973 & 0.034 & 121 & 0.099 & 0.092 & 104 & -0.115 & 0.096 & -1.236 & - & 0.217 & - \\
\hline
\end{tabular}

Those traits showing a normal distribution were compared by Student's $t$-test; the remainder, however, were compared by the Mann-Whitney test for which the standardized $z$-value is given. $P_{\mathrm{b}}$, probability resulting from sequential Bonferroni method. TL, thorax length (mm); ASN, number of antennal segments; TFN, number of testis follicles; SC, somatic condition; GC, gonadal condition. 
Table 2 Shapiro-Wilks test for normality $(W)$ and univariate tests (Student's $t$ or Mann-Whitney $U$ ) comparing seven variables between mating and nonmating female Eyprepocnemis plorans

\begin{tabular}{|c|c|c|c|c|c|c|c|c|c|c|c|c|c|}
\hline \multirow[b]{2}{*}{ Trait } & \multicolumn{3}{|c|}{ Shapiro-Wilks } & \multicolumn{3}{|c|}{ Nonmating females } & \multicolumn{3}{|c|}{ Mating females } & \multicolumn{4}{|c|}{ Comparison } \\
\hline & $N$ & $W$ & $P$ & $N$ & Mean & SE & $N$ & Mean & SE & $t / z$ & d.f. & $P$ & $P_{\mathrm{b}}$ \\
\hline $\mathrm{TI}$ & 57 & .981 & 政 & 128 & 7.4 & 0.039 & 129 & 7.410 & 0.0 & 0.1 & 255 & 0.867 & - \\
\hline ASN & 53 & 0.620 & $<0.001$ & 126 & 25.532 & 0.226 & 127 & 26.638 & 0.155 & -0.308 & - & 0.758 & - \\
\hline EDO & 201 & 0.859 & $<0.001$ & 102 & 0.559 & 0.024 & 99 & 0.599 & 0.023 & -1.281 & - & 0.200 & - \\
\hline EV & 250 & 0.928 & $<0.001$ & 126 & 3.614 & 0.245 & 124 & 4.311 & 0.228 & -2.038 & - & 0.042 & 0.210 \\
\hline TVE & 193 & 0.948 & $<0.001$ & 99 & 180.168 & 12.181 & 94 & 209.384 & 13.002 & -1.751 & - & 0.080 & - \\
\hline $\mathrm{SC}$ & 255 & 0.987 & 0.807 & 127 & -0.225 & 0.090 & 128 & 0.223 & 0.082 & -3.675 & 253 & $<0.001$ & 0.004 \\
\hline GC & 255 & 0.908 & $<0.001$ & 127 & -0.104 & 0.091 & 128 & 0.103 & 0.086 & -2.170 & - & 0.030 & 0.180 \\
\hline
\end{tabular}

Those traits showing a normal distribution were compared by the Student's $t$-test; the remainder, however, were compared by the Mann-Whitney test for which the standardized $z$-value is given. $P_{\mathrm{b}}$, probability resulting from sequential Bonferroni method. TL, thorax length (mm); ASN, number of antennal segments; EDO, ovarioles developing an egg; EV, egg volume; TVE, total volume of eggs; SC, somatic condition; GC, gonadal condition.

we have partitioned condition into somatic and gonadal conditions, both being the standardized residuals of the regression of weight (somatic or gonadal) on body size (represented by thorax length). The separate analysis of gonadal condition is very interesting for a species with a high last-male sperm precedence, as is the case for E. plorans (López-León et al., 1993), because it could be advantageous for males to recognize the females with the best gonadal condition, because these females could lay soon after mating and there would be less chance for sperm displacement by subsequent males. Our results have shown that although gonadal condition was higher in mating females than in nonmating ones (Table 2), the significance was lost after

Table 3 Logistic regression for mating status of Eyprepocnemis plorans as the dependent variable and those traits that in the univariate comparisons shown in Tables 1 and 2 gave $P<0.3$ as independent variables

\begin{tabular}{llrrr}
\hline Sex & Trait & $F$ & d.f. & $P$ \\
\hline Males & TL & 0.91 & 1,201 & 0.340 \\
& TFN & 0.74 & 1,201 & 0.392 \\
& SC & 0.53 & 1,201 & 0.468 \\
Females & EDO & 0.02 & 1,190 & 0.892 \\
& EV & 0.03 & 1,190 & 0.865 \\
& TVE & 0.96 & 1,190 & 0.328 \\
& SC & 23.62 & 1,191 & $<0.001$ \\
& GC & 0.27 & 1,190 & 0.603 \\
\hline
\end{tabular}

EDO, ovarioles developing an egg; EV, egg volume; TVE, total volume of eggs; SC, somatic condition; GC, gonadal condition; TL, thorax length ( $\mathrm{mm})$; TFN, number of testis follicles.
Bonferroni application. A similar result came from the analysis of egg volume, which could serve the same purpose. These results suggest that E. plorans males could have the ability to discriminate between gravid females and females which have recently laid, but they are not conclusive in this respect. Male choice experiments would probably give an answer to this question.

The present results have shown that mating frequency in $E$. plorans males does not depend on any of the morphological and physiological traits analysed, including body size and condition. Although there are many examples in the literature of a relationship between male body size or condition and mating success, there are also cases where no such association has been found, e.g. the damsel-

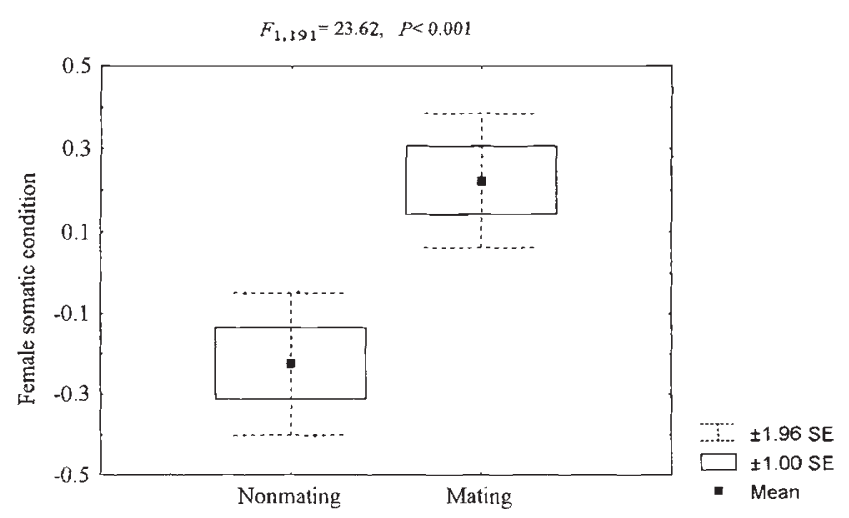

Fig. 3 Box and whisker plot showing somatic condition of mating and nonmating females. The ANOVA shown on the top corresponds to the logistic regression analysis shown in Table 3.

(C) The Genetical Society of Great Britain, Heredity, 79, 524-530. 
fly Enallagma hageni (Fincke, 1988), the horseshoe crab Limulus polyphemus (Loveland \& Botton, 1992), and the crickets Gryllus integer (Cade \& Cade, 1992) and G. firmus (Roff \& Fairbairn, 1993).

In females, however, somatic condition was revealed as a highly significant correlate of mating frequency: those females with good somatic condition showed a high probability of being caught while mating. As female fitness increases with mating frequency in E. plorans (Pardo et al., 1995a), the present results suggest that in this species females are subject to sexual selection in relation to somatic condition. Whether this is achieved by intrasexual competition or by male choice cannot be discerned from the present results, but the absence of significant correlation in mating pairs between female thorax length (a strength index) and male somatic condition (a quality index) $\left(r=0.091, F_{\mathrm{1}, 102}=0.857\right.$, $P=0.357)$ suggests the absence of female intrasexual competition. A similar analysis suggested the absence of male intrasexual competition $(r=0.121$, $\left.F_{1,101}=1.498, P=0.224\right)$, and the fact that males of this species do not sing, in contrast to many other grasshopper species, is another sign of a low male intrasexual competition.

There are few examples of sexual selection in females, and all of them are related to cases of sex role reversal (Arnold, 1994). Could E. plorans be another species with sex role reversal? A key factor that clearly could favour such a reversal is courtship feeding. In the Orthoptera, courtship feeding may be performed by means of external (Tettigonioidea) (Gwynne, 1984) or internal (Acridoidea) (Friedel \& Gillot, 1977; Butlin et al., 1987) spermatophores. In E. plorans, we have shown recently that males transfer proteinaceous substances in the ejaculate, and that these are incorporated into the eggs which the female subsequently lays, which explains why the rates of egg and embryo production are directly dependent of mating frequency (Pardo et al., 1995a). The fact that the increase in female fitness with mating frequency was apparent even though the females were fed ad libitum suggests that male nutrients are very important for egg production in $E$. plorans. In fact, virgin $E$. plorans females are reluctant to lay eggs, in contrast to Locusta migratoria where virgin females lay eggs at a rate comparable to that of mated females (Pardo et al., 1995b). In $E$. plorans it is possible that males transfer a quality factor with the ejaculate that might be important for egg production. It is well known that the E2 prostaglandin and other substances produced in the male accessory gland induce both vitelogenesis and oviposition in several insect species (Leopold, 1976).
There is no known case of a grasshopper showing sex role reversal, so it would be very interesting to investigate in future work the possibility that $E$. plorans is such a case. This could be approached by, for instance, the determination of the operational sex ratio, measuring remating time for each sex and male choice experiments.

In a species with strong last-male sperm precedence, like E. plorans (López-León et al., 1993), it should be advantageous for males to mate preferentially with those females that are ready to lay, in order to maximize paternity, and somatic condition could perhaps run in parallel to the signals used by males to identify females carrying mature eggs. Because females obtain ejaculate nutrients from males, they are prone to mate frequently because this increases their fitness through improving the rate of egg production (Pardo et al., 1995a). It would become advantageous for females to cheat males by simulating the signals that males use for mate choice. A possibility is that males detect ready-to-lay females because of their enlarged abdomen. If females with a better somatic condition have a higher facility for enlarging the abdomen despite lacking mature eggs, they could cheat males and thus gain more matings, the nutritional benefits obtained providing them a superior fitness. This could also explain why males do not seem to be able to mate preferentially with females with larger eggs (those ready to lay), thus avoiding sperm displacement.

\section{Acknowledgements}

We thank Jack H. Werren for perceptive comments. This study was partially supported by grants from the Dirección General de Investigación Científica y Técnica (no. PB93-1108) and the Plan Andaluz de Investigación, Grupo no. 3122 (Spain).

\section{References}

ANDERSSON, M. 1986. Evolution of condition-dependent sex ornaments and mating preferences: sexual selection based on viability differences. Evolution, 40, 804-816.

ANdersson, M. 1994. Sexual Selection. Princeton University Press, Princeton, NJ.

ARNOLD, S. J. 1994. Is there a unifying concept of sexual selection that applies to both plants and animals? Am. Nat., 144 (Suppl.), S1-S12.

ARNOLD, S. J. AND WADE, M. J. 1984a. On the measurement of natural and sexual selection: theory. Evolution, 38, 709-719.

ARNOLD, S. J. AND WADE, M. J. 1984b. On the measurement of natural and sexual selection: applications. Evolution, 38, $720-734$. 
ARNQVIST, G. 1992. Spatial variation in selective regimes: sexual selection in the water strider, Gerris odontogaster. Evolution, 46, 914-929.

BERRIGAN, D. AND lockE, S. J. 1991. Body size and male reproductive performance in the flesh fly, Neobellieria bullata. J. Insect Physiol., 37, 575-581.

BORTOlotTl, G. R. AND IKO, W. M. 1992. Non-random pairing in American kestrels: mate choice vs, intrasexual competition. Anim. Behav, 44, 811-821.

BUTLIN, R. K., WOODHATCH, C. W. AND HEWITT, G. M. 1987. Male spermatophore increases female fecundity in a grasshopper. Evolution, 41, 221-225.

CADE, w. H. AND CADE, E. S. 1992. Male mating success, calling and searching behaviour at high and low densities in the field cricket, Gryllus integer. Anim. Behav., 43, 49-56.

CARROLL, S. P. AND SALAMON, M. H. 1995. Variation in sexual selection on male body size within and between populations of the soapberry bug. Anim. Behav, 50, 1463-1474.

DARW1N, C. 1871. The Descent of Man and Selection in Relation to Sex. Murray, London.

DRONEY, D. C. 1992. Sexual selection in a lekking Hawaiian Drosophila: the roles of male competition and female choice in male mating success. Anim. Behav., 44, 1007-1020.

ENDi.er, J. A. 1986. Natural Selection in the Wild. Princeton University Press, Princeton, NJ.

FINCKE, O. M. 1988. Sources of variation in lifetime reproductive success in a nonterritorial damselfly (Odonata: Coenagrionidae). In: Clutton-Brock, T. H. (ed.) Reproductive Success, pp. 24-43. University of Chicago Press, Chicago.

FRIEDEL, T. AND GILLOT, C. 1977. Contribution of male produced proteins to vitellogenesis in Melanoplus sanguinipes. J. Insect Physiol, , 23, 145-151.

GWYNNE, D. T. 1984. Courtship feeding increases female reproductive succes in bushcrickets. Nature, 307 , $361-363$

HILL, G. E. 1990. Female house finches prefer colourful males: sexual selection for a condition-dependent trait. Anim. Behav., 40, 563-572.

JAMES, A. AND JAENIKE, J. 1992. Determinants of mating succes in wild Drosophila testacea. Anim. Behav., 44, $168-170$.

JOHANNESSON, K., ROLÁN-ALVAREZ, E. AND EKENDHAL, A. 1995. Incipient reproductive isolation between two sympatric morphs of the intertidal snail Littorina saxatilis. Evolution, 49, 1180-1190.

LAMUNYON, G. W. AND EISNER, T. 1993. Postcopulatory sexual selection in an arctiid moth (Utetheisa ornatrix).
Proc: Natl. Acad. Sci. U.S.A., 90, 4689-4692.

LEOPOLD, R. A. 1976. The role of male accessory glands in insect reproduction. Ann. Rev. Ent., 21, 199-221.

lóPEZ-LEÓN, M. D., CABRERO, J., PARDO, M. C., VISERAS, E. AND CAMACHO, J. P. M. 1993. Paternity displacement in the grasshopper Eyprepocnemis plorans. Heredity, 71, 539-545.

LÓPEZ-LEÓN, M. D., PARDO, M. C., CABRERO, J. AND CAMACHO, J. P. M. 1994. Dynamics of sperm storage in the grasshopper Eyprepocnemis plorans. Physiol. Entomol., 19, 46-50.

LÓPEZ-LEÓN, M. D., PARDO, M. C., CABRERO, J. AND CAMACHO, J. P. M. 1995. Evidence for multiple paternity in two natural populations of the grasshopper Eyprepocnemis plorans. Hereditas, 123, 89-90.

LOVElAND, R. E. AND BOTTON, M. L. 1992. Size dimorphism and the mating system in horseshoe crabs, Limulus polyphemus L. Anim. Behav. 44, 907-916.

PARDO, M. C., LÓPEZ-LEÓN, M. D., HEWITT, G. M. AND CAMACHO, J. P. M. 1995a. Female fitness is increased by frequent mating in grasshoppers. Heredity, 74, 654-660.

PARDO, M. C., LÓPEZ-LEÓN, M. D., CABRERO, J. AND CAMACHO, J. P. M. 1995b. Cytological and developmental analysis of tychoparthenogenesis in Locusta migratoria. Heredity, 75, 485-494.

PITNiCK, s. 1991. Male size influences mate fecundity and remating interval in Drosophila melanogaster. Anim. Behav. 41, 735-745.

PREZIOSI, R. F. AND FAIRBAirn, D. J. 1996. Sexual size dimorphism and selection in the wild in the waterstrider Aquarius remigis: Body size, components of body size and male mating success. J. Evol. Biol., 9, 317-336.

RIDLEY, M. 1988. Mating frequency and fecundity in insects. Biol. Rev., 63, 509-549.

ROFF, D. A. AND FAIRBAIRN, D. J. 1993. The evolution of alternate morphologies: fitness and wing morphology in male sand crickets. Evolution, 47, 1572-1584.

RUIZ, A., SANTOS, M., BARBADILla, A., QUESADA-DÍAZ, J. E., HASSON, E. AND FONTDEVILA, A. 1991. Genetic variance for body size in a natural population of Drosophila buzzatii. Genetics, 128, 739-750.

SANTOS, M., RUIZ, A., BARBADILla, A., QUESADA-DÍAZ, J. E., HASSON, E. AND FONTDEVILA, A. 1988. The evolutionary history of Drosophila buzzatii. XIV. Larger flies mate more often in nature. Heredity, 61, 255-262.

SMITH, R. L. 1984. Sperm Competition and the Evolution of Animal Mating Systems. Academic Press, New York.

IRIVERS, R. L. 1972. Parental investment and sexual selection. In: Campbell, B. G. (ed.) Sexual Selection and the Descent of Man 1871-1971, pp. 136-179. Aldine, Chicago. 